\title{
पंजाब घराने की वादन शेली में हाथ का रख रखाव
}

Ajaypal Singh

Ph.D. Research Scholar, Department of Music, Panjab University, Chandigarh

पंजाब घराना की वादन शैली का स्वरूप स्वतंत्र है, जो पखावज पर आधारित है। इसलिए यह भी एक भिन्न शैली के रूप में विकसित हुई है। इसलिए तबले में बड़ी-बड़ी गतें, परनें, चक्रदार परने, बड़े कायदे इस बाज की विशेषता है। इसमें चाँट की थाप पखावज की देन है। पखावज का सर्वाधिक प्रभाव पंजाब की वादन शैली पर पड़ा। पखावज में बोलों को बंद करके तबले पर बजाकर एक नयी शैली का निर्माण पंजाब वालों ने किया। कहीं कहीं आज बायें में स्याही के स्थान पर आटा लगाने की प्रंथा है जिससे वहां के तबले का जन्म पखावज से होना सिद्ध हो जाता है। पंजाब में बड़े-2 कायदे, लम्बी गतें, परनों व लयकारियों के काम का अधिक प्रचार है।

तबला वादकों द्वारा स्वतन्त्र रूप से पंजाब घराना का विकास हुआ। पंजाब के सबसे पुराने तबला वादक फकीर बख़्श खाँ हुए जिन्हें इस घराने का प्रतिव्यापक माना जाता है।1 फकीर बक्श खाँ और मियाँ कादिर बख़्श और हद्दू खाँ ने मध्य युग में पखावजी लाला भवानी प्रसाद से घराना की शिक्षा ली और फकीर बख़्श ने पखावज के खुले बोलों को बंद बोलों में परिवर्तित कर दिया और एक नई शैली का सृजन किया, जो पंजाब घराने के नाम से विख्यात हुई। फकीर बख़्श के पुत्र कादिर बख़्श थे। फकीर बख़्श के शिष्यों में करम इमामी खाँ, बाबा मलंग, मालन खाँ, फिराज खाँ और पं. बलदेव सहाय बनारस हुए और कादिर बख़्श के शिष्यों में लाल मुहम्मद खाँ, शौकत हुसैन खाँ, अल्लादियां खाँ और अल्लारखा है और अल्लारखाँ के सुपुत्र जाकिर हुसैन है।

पंजाब घराना की वादन शैली का स्वरूप स्वतंत्र है, जो पखावज पर आधारित है। इसलिए यह भी एक भिन्न शेली के रूप में विकसित हुई है। By adapting and modifying the bols of the pathaway and playing them on the table the Punjab gharana created a unique style of its own.2 इसलिए तबले में बड़ी-बड़ी गतें, परनें, चक्रदार परने, बड़े कायदे इस बाज की विशेषता है। इसमें चाँट की थाप पखावज की देन है। पखावज का सर्वाधिक प्रभाव पंजाब की वादन शेली पर पड़ा। पखावज में बोलों को बंद करके तबले पर बजाकर एक नयी शैली का निर्माण पंजाब वालों ने किया। कहीं कहीं आज वायें में स्याही के स्थान पर आटा लगाने की प्रंथा है जिससे वहां के बतले का जन्म पखावज से होना सिद्ध हो जाता है। पंजाब में बड़े-2 कायदे, लम्बी गतें, परनों व लयकारियों के काम का अधिक प्रचार है $1^{3}$

इस वादन शेली में धे तट, गिदगी केधी नट, धड़न्त, तड़न्न, धाधा, दुगं, दुगंतान आदि बोलों का सर्वाधिक प्रयोग होता है। इस घराने में ज़ोरदार व खुले बोलों का प्रयोग होता है। इस घराने में ज़ोरदार व खुले बोलों का प्रयोग स्पष्ट, शुद्ध तथा तैयारी से किया जाता है। पंजाब घराने में खुले बोलों का अधिक सामजस्य होता है। धिनाड़, धाती, नगनग, गदिन्नाड़ आदि बोलों का प्रयोग पंजाब घराने में विशेष रूप से होता है।

1 राम, सुदर्शन, तबले के घराने वादन शैलियाँ एवं बंदिशें, पृ. 45

2 Saxesena, Sudhir Kumar, The art of Tabla Rhythm, pg. 103

3 श्रीवास्तव गिरीश चंद्र, तबला वादन, पृ. 26 


\section{हाथ का रखाव}

"रख-रखाव" का अर्थ है-रक्षा, मर्यादा या परम्परा आदि का उचित निर्वाह। तबला वादन में तबला विद्वानों द्वारा हाथ की उँगलियों के संचालन के लिए निश्चित की गई मर्यादा या परम्परा का निर्वाळ ही हाथ का रख-रखाव कहलाता है। ${ }^{1}$ गायन में जिस प्रका कंठ द्वारा स्वरों की उत्पत्ति, सितार वादन में मिज़राब द्वारा बोलों का निकास, और नृत्य कला के अंतर्गत ध्वनि निष्पादन पर आघात द्वारा होता है ठीक उसी प्रकार अवनद्ध वाद्य तबले पर वर्णो का निकास दाँए पर उगँलियों द्वारा प्रहार से और बाँए पर हस्त द्वारा आघात से नादोत्पत्ति होती है।

तबला वादन की सम्पूर्ण वादन प्रक्रिया उसके हाथ के रखाव पर ही निर्भर (आश्रित) करती है। तबला वादन की शिक्षा ग्रहण करने से पूर्व हाथ का उचित रखाव अनिवार्य होता है। हाथ के रखाव का प्रभाव तबले की सम्पूर्ण प्रस्तुति पर पड़ता है। तबले पर उगलियों के सुनिश्चित संचालन से ही उचित नाद उत्पन्न होता है। तबले पर हाथ के सही रखाव द्वारा ही बोलों में स्पष्टता, माधुर्य और रस 'निष्पत्ति होती है, जिसके द्वारा शिष्य अपनी तबला प्रस्तुत को अत्यधिक प्रभावशाली बनानें में समर्थ हो सकता है। जिस तरह गुलाब के फूल से यदि उसकी सुगन्धि लुप्त हो जाए तो उसका कोई मोल नहीं रह जाता, ठीक उसी प्रकार यदि तबला वादन के समय हाथ का रखाव उचित न हो तो उससे निष्कासित हुए वर्णों का सौन्दर्य नष्ट हो जाता है।'

तबला वादन में बोल तभी परिपक्व होगे जब तबले पर हाथ रखाव सही ढंग से होगा। तबले की पुड़ी पर आघात करते समय हस्त में कडकपन नहीं होना चाहिए। हाथ के कड़पन के कारण बोलों को तैयारी में बजाना असम्भ है। बोलों की तैयारी के लिए हाथ में हल्कापन, कोमलता का होना अति अनिवार्य होता है, जिस कारण बोलों में रस निष्पति भी सहज आएगी।

घरानेदार गुरु द्वारा ही शिष्य तबले पर हाथ के रखाव की तकनीक को उचित ढंग से ग्रहण कर सकता है। तबला प्रस्तुति से पूर्व जब शिष्य तबले पर पहला बोल बजाता है, तबले पर आघात करता है, तो उस ध्वनि निष्पत्ति से यह सहज की ज्ञात हो जाता है कि शिष्य अब कौन से घराने का तबला प्रस्तुत करने जा रहा है, इसीलिए तबले पर उगलियों का व्यवस्थित संचालन, (उचित) अनुकूल वर्ण-निकास, वजनदार, व जोरदार प्रभावशाली बोलों की उत्पति, बोलों की सौन्दार्यात्मकता को प्रस्तुतिकरण, तैयारी बोलों में स्पष्टता सभी घरानेदार गुरु द्वारा प्रदान की गई शिक्षा और उनके निर्भर करता है। यही कारण है कि तबला वादन प्रस्तुति में हाथ के रखाव को मुख्य आधार माना गया है। तबले के प्रत्येक घराने में दाएँ तथा बाएँ हाथ की तर्जनी, मध्यमा, अनामिका, पृथक-पृथक होता है। "तबले पर हाथ रखते समय कलाई को तबले के पृष्इभाग से थोड़ा नीचे रखकर बजाने की दिल्ली तथा पूरब घराने की परम्परा है। पंजाब घराने में कलाई को तबले के पृष्ठभाग से समांतर रखकर बजाने की पद्धति अपनाई है।"

तर्जनी-हाथ के रखाव में तर्जनी उंगली को चाँट पर सीधे रूप से रखा जाता है और इसके अग्रभाव से आघात द्वारा ध्वनि निष्कासित की जाती हैं तर्जनी उंगली से पूरब बाज में लव पर और पश्चिम बाज में चाँट पर आघात किया जाता है। "पंजाब घराने में दाहिने तबले पर बोलों के निकास में तर्जनी उँगली को किनार की तरफ आघात किया जाता है। किनार पर लकड़ी के हिस्से पर तर्जनी द्वारा वर्णों की

1 शर्मा नीतू, डॉ. संगीत पत्रिका, अक्तूबर 2004, पृ. 45 
स्पष्टता को मध्य नजर रखते हुए ध्वनि निष्कासित की जाती है।" विभिन्न वर्णों का निष्कासन जैसे चाँटी पर 'ता', 'ना' एवं लव पर 'ति' स्याही पर है, के लिए तर्जनी उँगली का प्रयोग किया जाता है।

माध्यमा-स्याही पर बजने वाले वर्णों के निकास में मध्यमा उंगली की विशेष भूमिका निभाती है। पंजाब घराने में ति वर्ण का निकास स्याही पर मध्यमा व अनामिका द्वारा किया जाता है।

अनामिका - तबला वादन में दाहिने हाथ की अनामिका उंगली जो सम्पूर्ण हाथ के संचालन की मुख्य धुरी है के रखाव का अति महत्व है। अनामिका ऊँगली अग्र भाग को दाएँ तबले के अपनी ओर वाले भाग पर, स्याही के प्रारम्भिक स्थल पर स्थिर रखा जाता है। "दिल्ली, अजराड़ा, लखनऊ व फर्रखाबाद बाज में स्याही पर अनमिका अथवा तीसरी उँगली लगभग $20^{\circ}$ का न्यूनकोण बनाती हुई रखी जाती है। उंगली को अपेक्षकृत अधिक मोड़कर अथति लगभग $70^{\circ}$ का न्यूनकोण बनाती हुई रखते है और पंजाब बाज में इस उँगली को अन्य सभी की तुलना में कुछ सीधा करके रखा जाता है।

अनामिका उँगली का रखाव गुरु द्वारा प्रदान वादन शेली का परिचायक होता है। अनामिका उँगली की स्थिरता कम होते ही तबले पर बजाए जाने वाले वर्णों की ध्वनि में बदलाव आता है जिस कारण तबला वादन की मधुरता स्वतः ही समाप्त हो जाती है। इसी कारण अनामिका उंगली के अग्रभाग को अपने स्थान पर स्थिर रखना चाहिए। अनामिका उंगली की निश्चित स्थिरता पर ही तर्जनी उंगली के आघात द्वारा तबले पर नाद उत्पन्न होता है। तबले पर अनामिका उंगली का रखाव इस प्रकार का होना चाहिए, जिससे तबले पर आस बनी रहे। स्याही पर वर्ण निकास के लिए अनामिका उंगली का प्रयोग होता है।

अंगूठा- तबला वादन करते समय सर्वप्रथम हाथ के रखाव में अंगूठे की विशेष भूमिका है। "इसकी स्थिति तर्जनी उँगली के लगभग साथ होनी चाहिए। इसे न तो चिपकाकर रखना चाहिए और न ही लटके हुए रूप में। इन दोनों स्थितियों में हाथ की स्वतन्त्रता व लोच का हास होता है। इसका स्थान सुविधानुसार तर्जनी से $45^{\circ}$ अथवा कम हो सकता है।"2

हाथ का रखाव (डग्गा)

"डग्गे में स्याही बीचों बीच होती है। स्याही वाले भाग को तबले की तरफ मोड़ कर रखना डग्गे की सही दिशा कहलाती है। इससे डग्गे पर ध्वनि निकालते वक्त मीड़, गमक आदि का प्रयोग अधिक कुशलता से सम्भव है। उपरोक्त बातों पर यदि ध्यान न दिया जाये तो प्रारम्भ में कोई खास फर्क नहीं पड़ता है, परन्तु बाद में इसका दुष्परिणाम सामने आने लगता है जिसकी बैठक व्यवस्था, तबला-डग्गा रखने का अंदाज आदि सही न हो तो उसके वादन की विकृति परिलक्षित होती है। अतः सही बैठक व्यवस्था एवं तबले और डग्गे का सुव्यवस्थित रखाव एक कुशल-वादक बनने के लिए अत्यन्त आवश्यक है $\mathrm{I}^{\prime 3}$

इस प्रकार दाहिने तबले के रखाव में इस बात का ध्यान रखना चाहिए कि दाहिने तबले के हस्त संचालन में इस बात पर विशेष रूप से ध्यान रखना चाहिए कि दाहिने तबले को अपने से विपरीत

1 शर्मा नीलू, तबला वादन में हाथ का रखाव, संगीत पत्रिका-अक्टूबर 2004, पृ. 47-48

2 शर्मा नीलू, तबला वादन में हाथ का रखाव, संगीत पत्रिका-अक्टूबर 2004, पृ. 47-48

3 सिंह विद्यानिवास, संगीत कला विहार, अगस्त 2006, पृ. संख्या, 38 
दिशा में हल्का सा झुकाकर रखे, जिससे हाथ में तैयारी आ सके और हाथ आगे पीछे चल सके। इस बात पर भी विशेष ध्यान रखना चाहिए कि अगर तबला वादक दाहिने तबले को अधिक झुकाकर वादन करेगा तो इसका कुप्रभाव स्पष्टतः परिलक्षित होगा, जिसके कारण बोलों के निकास में अस्पष्टता दृष्टिपात होगी, जो कि तबला वादन में अशुद्धत पैदा करेगी तथा इसी प्रकार अत्यधिक झुके तबले पर वादन करने से हाथ की कलाई का हिस्सा ऊपर की ओर उठ जाता है, जो सौन्दर्यपरक न होकर सौन्दर्यहीन लगता है।

\section{संदर्भ ग्रंथ सूची}

राम सुदर्शन, तबले के घराने वादन शैलियाँ, कनिष्क पब्लिशर्स, दिल्ली, प्र. सं. 2008

परांजपे शरच्चंद्र श्रीधर, भारतीय संगीत का इतिहास, चौखम्बा संस्कृत सीरीज आफिस, वाराणासी, प्र. स. 1969 शुक्ल योगमाया, तबले का उद्गम विकास एवं वादन शैलियाँ, हिन्दी माध्यम कार्यन्वय, निदेशालय दिल्ली विश्वविद्यालय, प्र. सं. 1987

सरल भीमसेन, तबले संगत संगत एवं कलाकार, संगीत कार्यालय, हाथरस, उ. प्र. पंचम सं. 1994 श्रीवास्तव, अवनद्ध वाद्य (तबला), विभोर प्रकाशन अमृतसर, प्रथम सं. 2010 पत्र-पत्रिकाएँ

संगीत मासिक पत्रिका, संगीत कार्यालय, हाथरस, उ. प्र. जनवरी- फरवरी 1969, 1976, 1978, 2004 संगीत कला विहार, संगीत कार्यालय, हाथरस, 2006 